\section{Quality of Care}

Guest editors: M. Krausz (Hamburg), W. Fuchs (Zurich)

The research and the discussion on quality of care is a key issue in clinical addiction research these days. Quality assurance systems are also discussed under the aspect of restructuring therapy systems, and therefore they affect a wide range of political, clinical and research problems. We will try to present a thorough general view of the basic epidemiological and clinical problems, the documentation standards as well as a survey of the standards of care at a European level.

\section{Addiction Research in Central and Eastern Europe}

Guest editors: Janusz Sieroslawski (Warsaw), Paul Griffiths (London)

The political and social changes that have occurred and are occurring in Central and Eastern Europe have been accompanied by dramatic changes in both the scale and nature of substance misuse in the region. There is an urgent need to better understand these changes if the potential for serious health consequences, both for the area and neighbouring countries, is to be avoided. With regard to drug misuse, prevalence appears to have gone, in some areas, from virtually zero to a level comparable with western European countries. Despite the importance of understanding the changes that are occurring, there remains a chronic lack of contemporary quality research information on the area. To help remedy this problem, European Addiction Research is producing a special issue on the region. Submissions are invited that address this topic on substance use and contributions from researchers based in the region are particularly welcome.

\section{Psychotherapy in the Treatment of Addiction}

Guest editors: G. Woody (Philadelphia), M. Krausz (Hamburg)

Especially in pharmacotherapy of addiction, many new approaches are on the way, whereas in psychotherapy and psychosocial care, only little research has been done. Nevertheless, the great importance of psychotherapy in addiction treatment is undoubted. In this issue, new developments, especially in standardised approaches and experiences from the US, are presented to support the exchange and research in these fields.

\section{Adequacy of Drug Abuse Treatment and Care in Europe: Ethical Aspects, Support Needs, Professional Standards and Efficacy (ADAT)}

Guest editors: A. Uchtenhagen (Zürich), C. Goos (Kopenhagen)

Evaluation research on treatment and care of drug-related conditions and drug dependence has made much progress in recent years, resulting in an improvement of services as well as program-client matching. However, evaluation of effectiveness and even cost-effectiveness of services and service systems does not answer the overall question if and how services respond to treatment and support needs in a given population. This was the starting point for ADAT: a project researching the adequacy of treatment (helping?) systems to treatment and support needs, to professional and to ethical standards. The European Office of World Health Organisation has mandated the Addiction Research Institute in Zurich to co-ordinate the project. Participating countries are the Czech Republic, Denmark, Germany, Greece, Italy, the Netherlands, Poland, Spain, Sweden and Switzerland. A manual on ethical aspects, based on available information from participating countries, concepts and instruments for the determination of treatment needs, clarification of professional and quality standards, identification of indicators and assessment instruments for measuring effectiveness and cost-effectiveness of treatment and care, is the product expected from the project. The main results will be presented and discussed in an international perspective.

\section{Treatment of Alcohol Addiction \\ Guest editor: Christian Haasen (Hamburg)}

The treatment of alcohol addiction involves a number of different components dealing with various aspects of the course of addiction. These components are very different in nature and not necessarily based on the same principles of therapy. Nonetheless, they form part of the complex nature of addiction treatment for alcoholism. Treatment components can be divided into four main categories according to the course of addiction: the first group has to deal with motivation to detoxification, the second group comprises the detoxification programmes themselves, the third group concerns the immediate followup, while the fourth group includes rehabilitation programmes. Despite certain standards in these treatment components, there are still significant differences in treatment programmes from one region to another. These differences will be presented and discussed in the next issue of European Addiction Research.

\section{KARGER}

(C) 2001 S. Karger AG, Basel

Fax + 41613061234

E-Mail karger@karger.ch

www. karger.com
Accessible online at:

www. karger.com/journals/ear 